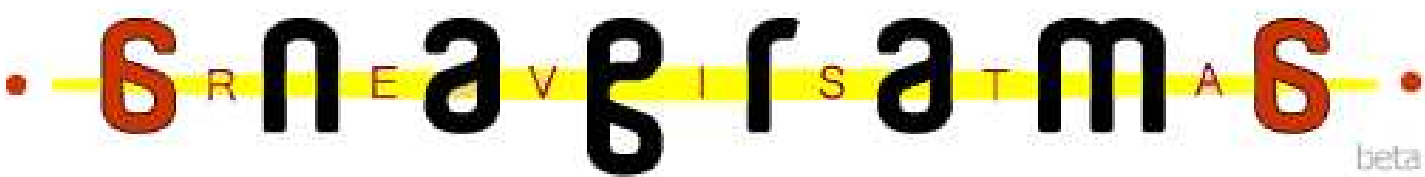

\section{mídia e Religião: o Ponto de Luz no discurso midiático lurdiano ${ }^{1}$}

\section{Juliano Pires da Rosa?}

Kellen dos Santos Severo ${ }^{3}$

Uiviane Borelli

\section{Resumo}

A midiatização da religião tem se consagrado como a principal forma de operacionalização em diversas ordens e denominações religiosas, dentre as quais se destaca a da Igreja Universal do Reino de Deus (IURD). Nesse contexto, a existência de distintos formatos do programa iurdiano Ponto de Luz permitiu detectar e relacionar as diferentes formas de enunciação e as estruturas utilizadas nas duas versões transmitidas pela Rede Record e Rede TV!, de São Paulo, e pela TV Pampa/ Rede TV!, de Santa Maria, RS. A pesquisa também aponta de que forma o discurso religioso iurdiano se remodela às técnicas e aos enunciados típicos do campo midiático.

Palauras-chaue: Midiatização; Enunciação; Campos Sociais; Religião; IURD.

\section{Introdução}

Com o advento e a expansão do fenômeno de midiatização, o entrecruzamento dos diferentes campos sociais tem se tornado freqüente e gerado, como conseqüência dessa proximidade, a apropriação dos modos operacionais e discursivos específicos de um com as ideologias e aplicações de outro. Essa relação de aproximação tem adquirido considerável visibilidade devido ao estreitamento das fronteiras entre o campo midiático e

\footnotetext{
${ }^{1} \mathrm{O}$ artigo resulta de parte do projeto de pesquisa "Mídia e Religião: Um estudo dos novos dispositivos de contato entre o mundo da fé e o fiel', orientado e coordenado pela professora Dr. Viviane Borelli e financiado pelo CNPq (Edital Universal 2007).

2 Estudante de Graduação, $8^{\circ}$ semestre do Curso de Jornalismo da UNIFRA-RS. Email: julianopires@hotmail.com

${ }^{3}$ Jornalista formada pela UNIFRA-RS. Email: kellensevero@ hotmail.com

${ }^{4}$ Professora doutora do Centro Universitário Franciscano (Unifra) e orientadora da pesquisa.
} 
religioso, característico, especialmente, das igrejas neopentecostais e, em especial, da Igreja Universal do Reino de Deus (IURD).

O programa Ponto de Luz, transmitido pela Rede Record e Rede TV!, de São Paulo, e pela TV Pampa/Rede TV!, de Santa Maria, revela como a IURD tem se utilizado da mídia televisiva como forma de reforçar a fé pregada nos templos aos seus fiéis e de atrair potenciais membros. Diante deste quadro, a pesquisa buscou analisar o discurso enunciado através da versão nacional e local do programa e quais elementos utilizados são compartilhados e específicos de cada um.

Com objetivo de fazer um estudo exploratório, inicialmente, foi gravado o programa Ponto de Luz em cada uma das emissoras: Rede Record, Rede TV! e TV Pampa/Rede TV! durante uma semana. Para fins de análise, foram selecionadas, aleatoriamente, uma edição do programa nacional e uma do local para, então, fazer uma leitura das suas estratégias enunciativas. A partir da descrição dos programas foram extraídos elementos para a comparação e análise de suas semelhanças e singularidades.

Primeiro, faz-se uma revisão dos conceitos de midiatização, campos sociais e enunciação. Depois, as relações entre a mídia e a IURD são discutidas para, então, fazer a descrição e a análise dos programas.

\section{A midiatização da sociedade}

Faz parte do senso comum dizer que vivemos em uma sociedade midiatizada. Mas o que isso, efetivamente, significa? Essa é uma questão que assola diversos autores. Rodrigues (1999) classifica o atual momento da vida em sociedade como um fenômeno em que a mídia ajusta e hierarquiza olhares perante a realidade. De acordo com o autor, hoje, a percepção do mundo depende também de complexos dispositivos de midiatização que acabam demarcando o ritmo da vida e, também, "sobrepondo-se cada vez mais não à nossa percepção imediata do mundo, mas também aos ritmos do funcionamento das instituições" (RODRIGUES, 1999: 1).

É nesse sentido que hoje se vive um amplo processo de midiatização o qual abrange toda a sociedade. Ou seja, os campos, na definição de Rodrigues (1999) ou as instituições, segundo Verón (1997), são afetadas por lógicas e características midiáticas. A mídia exerce uma ampla representação na sociedade. De acordo com Verón (1997), a sociedade midiática é caracterizada pela instalação das mídias que representam através de múltiplos signos. 
Nesse contexto, Fausto Neto (2005) considera que é a midiatização que produz de fato a afetação das formas de vida tradicionais, por uma qualificação de natureza informacional - tecnologia societal. "A inclinação no sentido de configurar discursivamente o funcionamento social em função de vetores mercadológicos e tecnológicos é caracterizada por uma prevalência da forma sobre conteúdos semânticos" (FAUSTO NETO: 2005: 9).

Quanto mais midiatizada uma sociedade, tanto mais ela se complexifica. O processo de midiatização do real é tido como um mecanismo difuso, isto porque carrega no eixo principal processos altamente imbricados com o ser no mundo. A midiatização não pode ser apenas lida como a interferência dos meios de comunicação na realidade, já que é um conceito muito mais amplo, capaz, inclusive, de alterar processualidades. "Ao invés do ato social, a rede. Do vínculo, o fluxo. Do contrato social, à terceirização generalizada. Referências fundacionais são mandadas para os ares, conseqüências da lógica reinante da sociedade segundo a qual 'vivemos no ar'” (FAUSTO NETO, 2005: 4).

No caso da midiatização da religião, têm sido desenvolvidos alguns estudos atuais para compreender como as relações entre os campos midiático e religioso mudam com o passar dos tempos e os modos através dos quais, atualmente, a religiosidade se configura ${ }^{5}$.

Nesse processo, algumas questões são centrais, como entender em que medida esse processo de midiatização da religião reconfigura o próprio conceito de religiosidade, apontando para outros modos de se vivenciar a religião. A presença, o trabalho e os mecanismos de funcionamento das mídias têm afetado os modus operandi do campo religioso, que se reestrutura para continuar tendo acesso aos seus fiéis.

Agora, o campo religioso passa a operar também a partir de lógicas que são midiáticas, pois é o trabalho dos dispositivos midiáticos que garante não só visibilidade, mas, também, permanência junto aos demais campos e os diferentes públicos que precisam ser atingidos.

De acordo com Gomes (2006: 2) a lógica do templo muda, passando de relações diretas e dialogais para uma lógica de mídia, que se dirige a um público anônimo e disperso. Para o autor, nesse processo de midiatização da religião, o conteúdo da

\footnotetext{
${ }^{5}$ Especialmente estudos de pesquisadores ligados à Universidade do Vale do Rio dos Sinos, como de Antonio Fausto Neto, Pedro Gilberto Gomes, Attilio Hartmann, Luis Ignacio Sierra Gutiérrez, Paulo Roque Gasparetto, Viviane Borelli, Ricardo Fiegenbaum Zimmermann, Alexandre Dresch Bandeira, Micael Vier Behs, entre outros, que integram obras como Sierra Gutiérrez, Luis Ignacio (org.) Religião da mídia: Credibilidades em tensão. Unisinos, São Leopoldo, RS, Brasil, 2006. CD Edição Limitada.
} 
mensagem dá lugar a processos de encenação, onde a "comunidade de fé sai de cena, dando lugar ao conjunto de telespectadores".

Nesse sentido, a IURD parece ser o caso mais proeminente de Igreja que faz uso da mídia e que opera segundo pressupostos que são mais característicos do campo midiático que do religioso. As relações entre os campos da mídia e da religião têm sido objeto de algumas pesquisas atuais e, tendo em mente a questão central apresentada, faz-se necessário discutir estudos que enfocam especificamente o caso da IURD, sua constituição enquanto Igreja, suas relações com as mídias e seus produtos midiáticos.

\section{0 ambiente midiático iurdiano}

Fundada em 9 de julho de 1977 pelo bispo/empresário Edir Macedo Bezerra, a Igreja Universal do Reino de Deus (IURD) começou suas atividades em um espaço alugado na zona norte do Rio de Janeiro. Sete anos depois, Macedo adquiriu a Rádio Copacabana, a primeira estação do que mais tarde viria a ser conhecido como a Rede Aleluia. De acordo com reportagem do jornal Folha de São Paulo ${ }^{6}$, a IURD é a maior proprietária de emissoras de televisão (23) e de estações de rádio (40) no país, como a Rede Mulher, a Rede Família, a CNT e a Rede Record. Outro mecanismo de que a IURD se vale para veicular sua programação, além da compra de emissoras próprias, é o aluguel de horários em outras mídias abertas, como acontece com a Rede TV! E a TV Gazeta. A IURD tem cerca de 45 horas semanais de programação na TV aberta brasileira, contabilizando-se apenas os horários da Rede Record e Rede TV!.

A IURD conta também com algumas publicações impressas como as revistas $A$ Visão da Fé e Plenitude - carro-chefe da mídia impressa, lançada em 1985 - e os jornais Correio do Povo (gaúcho, adquirido em 2007), Hoje em Dia (IURD) e a Folha Universal - publicada desde 1992 com uma tiragem superior a 2,3 milhões de exemplares e de distribuição gratuita em todo o país. E, integrando a "redoma das mídias" caracterizada por Behs (2009: 28), um dos maiores investimentos da IURD se faz presente na internet: o site Arca Universal, que reúne, além da ampla variedade de canais com acesso a conteúdos de cunho jornalístico, evangélico e de entretenimento, as versões online dos produtos midiáticos.

\footnotetext{
${ }^{6}$ Dados presentes na reportagem da jornalista Elvira Lobato, do jornal Folha de São Paulo, intitulada "Igreja Controla maior parte de TVs do país", de 15 de dezembro de 2007. Acessado em 23/06/2009 e disponível em: http://www1.folha.uol.com.br/folha/brasil/ult96u373563.shtml.
} 
Assim como acontece com as transmissões da Record, alguns veículos impressos também passaram a circular no exterior. Para além das mídias tradicionais, a IURD também investe financeiramente em gráficas, gravadoras, portais on-line, confecção de CDs e impressão de livros como forma de ampliar a "vitrine digitalizada" e a circulação de produtos e mercadorias vinculados à fé Universal.

Criada sob a denominação do neopentecostalismo, em que os meios de comunicação passam a integrar a forma de fazer religião, a constituição da Igreja Universal transita entre os conceitos de igreja eletrônica e tele-evangelismo. Para Gomes (2006) a diferença entre os dois conceitos se apresenta da seguinte forma; A Igreja eletrônica é compreendida como aquela que faz uso de dispositivos para atingir os seus fiéis seja de forma presencial ou em suas residências, substituindo a antiga forma de se fazer religião através da presença física nos templos. Já o tele-evangelismo é concebido como uma prática de evangelização à distância através de técnicas radiofônicas e/ou televisivas que possam garantir que as doutrinas das Igrejas cheguem até os ouvintes/telespectadores.

Nesse sentido, as relações que antes eram estabelecidas dentro do espaço dos templos, caracterizadas como relações "com rosto", perdem essa identidade e se tornam "sem rosto" na medida em que passam a depender da mediação de dispositivos midiáticos (BEHS, 2007: 7). A Universal, no entanto, aliou os dois conceitos - de igreja eletrônica e tele-evangelismo - em suas práticas midiáticas e modo de fazer religião a fim de propagar seus ideais enquanto denominação, mantendo a membresia em contato direto e permanente com suas mídias.

A apropriação de diferentes mídias pela IURD fez com que ela própria tivesse que adaptar sua religiosidade e discurso aos processos sócio-técnicos dos meios que passou a utilizar. Behs (2009: 22) afirma que a IURD representa um conceito de "igreja midiática", em que "a descrição desta ambiência faz pensar que a IURD não apenas detém uma complexa plataforma de veículos de comunicação massiva, como também faz operar a sua religiosidade nas formas de mídia".

Outra característica da "redoma das mídias" iurdianas que reforça a mediação, é a retroalimentação, através da qual um veículo oferece suporte a outro e que, ao mesmo tempo em que reforça o caráter de ambiente midiatizado, mantendo o poder simbólico da Universal, permite que cada uma das mídias tenha inserções particulares no cotidiano dos fiéis e da sociedade. Behs (2009) destaca que os processos midiáticos desenvolvidos pela 
IURD possuem uma dupla função: reproduzir a atividade litúrgica para além dos templos e afirmar a identidade e o funcionamento da igreja segundo os princípios da midiatização.

Entretanto, a relação da IURD com as mídias utilizadas possui um traço particular: "ao mesmo tempo que se utiliza da mídia e de suas peculiaridades, a denominação [Igreja Universal] também nega elementos fundamentais do meio" (FONSECA, 2003a: 45). O autor destaca o exemplo da televisão, que se transforma em mais um meio pelo qual a IURD pode agir e integra a "estratégia de manutenção, expansão e legitimação sociopolítica".

Porém, embora exista essa particularidade, Behs (2009: 26), destaca que a Record "representa um dos mais importantes elos da ambiência midiática a oferecer as condições necessárias para a existência da Universal”.

$\mathrm{O}$ autor caracteriza de que forma o modus operandi da fé iurdiana se reconfigura para ocupar o espaço televisivo da Record:

\begin{abstract}
A coloquialidade dos ministrantes de culto; a gestualidade da membresia; o som; a iluminação; as escrituras projetadas eletronicamente ao fundo do púlpito iluminado com luzes de neon; o olhar do pastor que se dirige ao público, mas também às câmeras; o isolamento acústico dos templos; e a dinâmica da celebração, dividida em rezas curtas, testemunhos rápidos, cantos, aplausos adorações apontam para a intensificação do movimento de convergência entre as práticas religiosas e as lógicas midiáticas (BEHS, 2009: 59).
\end{abstract}

A midiatização da fé, segundo os princípios da IURD, atua de maneira contrária como acontece em outras denominações, onde esse processo é utilizado como forma de arrecadação de recursos. Os dispositivos midiáticos, ao se posicionarem a serviço do discurso iurdiano, adquirem o objetivo de "divulgar seus produtos, reforçar os fiéis que compõem a atual membresia e atrair potenciais seguidores, os quais pagarão pelos serviços que utilizarão e poderão engrossar o seu rol de dizimistas" (FONSECA, 2003b: 278). Fato que comprova a importância da manutenção dos membros e do apoio dado por estes, tanto no formato de testemunho e assistência, quanto contribuição financeira, pois, dessa forma, asseguram a posse e a presença da IURD na mídia.

Tendo em vista que a televisão seja um dispositivo por excelência de enunciação, já que os contratos que ela oferta se efetivam a partir desses processos de produção de sentidos, faz-se necessário conhecer o conceito de enunciação para depois poder analisar o programa televisivo religioso Ponto de Luz. 


\section{Enunciação e dispositivo teleuisiuo}

Muitos autores divergem sobre o conceito de enunciação: uns aprofundam mais questões lingüísticas ou semióticas e outros interpretam os modos de dizer a partir de gêneros jornalísticos, como Charaudeau (2007). Segundo ele, fala e imagem estão dissociadas em suas significações, ou seja, cada uma tem sua própria maneira de ser e realizar. No entanto, elas se fundem quando no processo de transmissão da mensagem:

Um sistema semiológico próprio, cujo funcionamento discursivo constrói universos de sentidos particulares, podendo a imagem jogar mais com a representação do sensível, enquanto a palavra usa da evocação que passa pelo conceitual, cada uma gozando de certa autonomia em relação a outra (CHARAUDEAU, 2007: 109-110).

Os modos de dizer são estratégias inerentes ao próprio funcionamento dos discursos. Todavia, a enunciação não se mostra com clareza, já que é preciso esmiuçar os seus sentidos. Rodrigues (1994: 145) sintetiza como podemos definir enunciação: "no domínio da pragmática da comunicação é o facto de o sentido ser, ao contrário da significação, não da ordem do dito, daquilo que é explicitamente pronunciado, mas da ordem daquilo que é pressuposto”.

O entendimento acerca das questões explicitadas em programas de televisão ou em outros objetos midiáticos vai ao encontro das vivências de cada indivíduo. O consumo e a interpretação das imagens e das narrativas passam por filtros, compostos por elementos pertencentes e pertinentes à realidade de cada um. Na televisão, a imagem, de acordo com Charaudeau (2007), é consumida como um bloco semântico compacto, que seja pela transparência, ou opacidade, é pouco apropriada para discriminar, analisar e explicar.

A televisão é um dispositivo que carrega em si um poder de conferir legitimidade aos assuntos, campos e indivíduos que refere. A TV é um dispositivo central no processo de reconhecimento do real por parte das pessoas, pois produz e enuncia distintos sentidos. E essa produção de sentidos ocorre de forma singular. Ela é perpassada por questões de várias ordens, como conceitua Rodrigues (1994: 146): "O dispositivo da enunciação, processo que fixa o sentido daquilo que é enunciado, embora seja imanente ao conjunto daquilo que é dito e do seu sentido, é, portanto autônomo em relação ao processo da significação codificada".

Os processos comunicacionais estão em constante transformação. Com isso, é preciso que se entenda a infinitude deste processo. Todavia, a intenção é que sejam percebidos os meandros pertencentes à relação interlocutiva. Para que haja comunicação é 
necessário que o código seja o mesmo, assim, se processarão trocas de informações e, conseqüentemente, de sentidos. Os imbricamentos destas trocas são alvo constante da enunciação, processo responsável por detalhar e analisar os modos como são ditos os enunciados e os pressupostos da explicitação verbal e não-verbal.

Nesse contexto, passa-se para a descrição do objeto de pesquisa, o Programa Ponto de Luz para depois poder analisar alguns dos modos de enunciação dos seus distintos apresentadores.

\section{O Programa Ponto de Luz}

O Ponto de Luz é um programa de pregação, exibido na programação da IURD na madrugada da Record, que vai aproximadamente da $1 \mathrm{~h}$ às $7 \mathrm{~h}$, e na Rede $T V(\mathrm{SP})$, durante a tarde, a partir das $13 \mathrm{~h}$. O programa é apresentado por um pastor no estúdio, onde ao fundo fica uma televisão LCD com a logomarca do Ponto de Luz estampada.

O formato do programa é híbrido, com cabeças ${ }^{7}$ enunciadas pelos pastores no estúdio, onde geralmente anunciam testemunhos de fé, com depoimentos de pessoas que passaram ou passam por dificuldades e que superaram esses problemas. Além disso, ele chama 'intervalos', espécie de vinhetas, nas quais são exibidas imagens de templos lotados onde aparecem pessoas cantando e louvando. Os temas dos programas são problemas de saúde, de relacionamento, família. Os pastores se apropriam dessas temáticas para pregar a doutrina da IURD. A partir da gravação do programa, da Rede Record e Rede TV!, realizada durante uma semana, nota-se que o Ponto de Luz aborda, geralmente, os temas trabalhados nas campanhas específicas da igreja e a programação habitual dos cultos: por exemplo, terça-feira é o dia da sessão espiritual do descarrego, da rosa do descarrego, da corrente dos 70 apóstolos e da limpeza espiritual. A sexta-feira é o dia da cruz iluminada; e do grande desafio da cruz. Já o domingo é o dia da reunião do encontro com Deus, da concentração de fé e milagres e é considerado o "domingo da transformação".

A vinheta de abertura é composta por imagens de pessoas desesperadas. São intercaladas cenas chocantes, como de uma mulher que tenta se jogar de um prédio e é impedida por um homem. O cenário é composto, basicamente, por uma tela de plasma ao fundo com o logo do Ponto de Luz e por um púlpito, de onde o bispo/apresentador realiza a condução do programa e expõe os depoimentos.

\footnotetext{
${ }^{7}$ Texto enunciado pelos jornalistas/apresentadores que vem antes da reportagem ser veiculada. Contém o lead (o quê, quando, onde, por que, para quem, com quem) da matéria. Ou seja, o texto que chama a matéria.
} 
$\mathrm{Na}$ apresentação do programa duas câmeras trabalham com ângulos diferentes da imagem do pastor, uma com plano mais aberto e outra com plano mais fechado. $\mathrm{O}$ tom de voz do bispo/apresentador é convidativo e cativa o telespectador.

Mesmo que aborde temas semelhantes, o Ponto de Luz se apresenta em distintos formatos. Esses variam de acordo quem os apresenta, com o local onde é produzido e o canal em que é veiculado. Busca-se compreender como um produto midiático religioso que possui uma única denominação se apresenta de distintos modos, ofertando e produzindo, conseqüentemente, diferentes sentidos.

Para tal, foi gravada uma semana de programação em três emissoras distintas: Rede Record, Rede TV! e Rede Pampa de Comunicação. A partir de pré-leitura e pré-análise dos materiais, foram identificadas diferenças e semelhanças que incluem: duração, cenário, abrangência e linguagem.

Para fins de análise, o critério de seleção foi a recorrência, ou seja, elementos que mais se assemelham nos diferentes programas. Assim, toma-se como corpus da pesquisa dois deles: dias 16 de maio (Record) e 24 de abril (Rede Pampa), ambos de 2009. Selecionou-se um Ponto de Luz de cada formato para justamente ser possível compreender as diferentes estratégias adotadas pelos produtores através de distintos modos de enunciação dos apresentadores.

\section{Proprama Ponto de Luz - Rede Record/Rede TU!}

Tanto na Record, como na Rede TV!, a apresentação é revezada diariamente entre bispos e pastores da Igreja e que possuem maior visibilidade como o Bispo Romualdo Panceiro e os pastores Edson Costa e Jadson Santos.

O cenário é o mesmo empregado em outros programas como o Saindo da Crise, composto por uma tela de LCD, que exibe o logo do programa transmitido, e é acrescido um púlpito, utilizado apenas pelo Bispo Romualdo. O cenário também é 'modificado' quando são realizados depoimentos 'ao vivo', instante em que o apresentador se desloca de onde estava realizando a apresentação para outro ponto do estúdio. Então, ele passa a dispor de dois sofás para a realização de uma entrevista com algum fiel. Outras formas de modificação do cenário também são aplicadas para a realização de depoimentos-entrevista, que utilizam, aleatoriamente, um fundo escuro com a presença de uma única luz ao fundo, de um cenário montado que é similar ao utilizado no programa ou mesmo de ambientes externos. 
O formato do programa é composto, em sua essência, por depoimentos e relatos feitos por féis da IURD, comentados e/ou previamente introduzidos e contextualizados pelos apresentadores. Esses depoimentos, no entanto, têm uma diferenciação em seus formatos que acaba relativizando suas durações e, conseqüentemente, o número que vai ao ar. Os depoimentos se dividem da seguinte maneira: reportagem, confissão e entrevista.

No depoimento-reportagem há testemunhos que se utilizam da linguagem e elementos técnicos empregados no jornalismo televisivo, como sonora ${ }^{8}$, passagem ${ }^{9}$ e off ${ }^{10}$, além de pequenas inserções da 'entrevistadora-repórter'. No depoimento-confissão há testemunhos relatados pelos fiéis dentro dos próprios cultos e diante dos demais, em que o bispo ou pastor questiona quais foram os momentos ruins vividos pela pessoa e de que forma a IURD modificou suas vidas.

Já no depoimento-entrevista há testemunhos que se dividem em duas formas: a primeira é a realização de uma conversa em que o apresentador encontra-se sentado em um sofá junto com o fiel-entrevistado, dentro do estúdio. A segunda consiste em respostas dadas à câmera pelo fiel e por algum outro membro da família com o qual a pessoa convive. Eles passam a relatar suas experiências de maneira que mostrem o ponto de vista de quem estava fora da situação e de quem estava vivenciando o "fundo do poço", ou então que revelem os dois lados de um determinado conflito, como é o caso das brigas entre casais, por exemplo.

Em alguns casos, são exibidos trechos de cultos realizados pelo próprio Edir Macedo, selecionados de acordo com a abordagem que o apresentador está utilizando naquele momento específico. $\mathrm{O}$ programa também exibe depoimentos gravados para o quadro Fogueira Santa de Israel, que aborda especificamente as dificuldades e crises financeiras enfrentadas e superadas pelos fiéis.

No dia 16 de maio, o apresentador foi o Bispo Romualdo Panceiro, que inicia comentando a importância de as pessoas terem fé em Deus e de como isso pode as auxiliar a sair do 'buraco' causado por problemas de todas as ordens. Em seguida, refere as dificuldades enfrentadas diariamente e cita o exemplo do depoimento-reportagem que vai ser transmitido na seqüência.

\footnotetext{
${ }^{8}$ Sonoras são as entrevistas que compõem as reportagens jornalísticas de televisão.

${ }^{9}$ Passagem é o espaço da matéria no qual o repórter aparece. Também pode ser chamado de boletim.

${ }^{10}$ Off é o texto que é coberto por imagens e lido pelo repórter.
} 
O principal assunto dos relatos são as desgraças vividas pelos fiéis antes da conversão. E cita o exemplo de uma senhora desesperada que o procurou e de como a ajudou a entender o funcionamento da fé:

\begin{abstract}
'Eu perguntei 'a senhora crê em Deus?' e ela 'muito!'. E eu disse então 'como pode a senhora crer em Deus e viver da forma que a senhora está vivendo? Porque era para a senhora estar bem financeiramente, era para senhora estar saudável, era para a senhora, por exemplo, dormir bem, ter paz” (Bispo Panceiro, Ponto de Luz, 16 de maio de 2009).
\end{abstract}

Durante os depoimentos, o gerador de caracteres (GC) exibe um "resumo" das experiências que estão sendo descritas e relatadas pelos interlocutores. Os depoimentosreportagem, em especial, exploram o lado sentimental dos telespectadores, de maneira que aqueles que estejam assistindo se comovam com os protagonistas, que frequentemente choram ao revelarem seus dramas pessoais.

Os casos apresentados começam atenuando os problemas vivenciados pelos depoentes e, gradualmente, vão se inserindo novos agravamentos e dificuldades até chegar a um ponto em que se instaure uma "crise" e que as perspectivas não mais existam, e que a saída pareça impossível senão pelo advento da Igreja, em específico da IURD. As frases de Panceiro explicam bem a lógica do programa e da fé iurdiana:

\footnotetext{
"Não basta a gente ter uma crença em Deus, ter uma fé em Deus. Essa fé tem que ser colocada em prática, senão não funciona (...) e o impossível vai se tornar possível”. As "viradas" e mudanças acontecidas nas vidas dos fiéis também são chamadas de revoltas: "Aliás, falando em revolta, essa era a revolta de Gideão, porque ele acreditava em um Deus tão grande, e vivia uma vida de sofrimento, uma vida de miséria, uma vida de dor que quando Deus apareceu pra ele dizendo 'eu sou contigo', então ele disse 'se o senhor é comigo, então porque me sobreveio tudo isso?'. Quer dizer, é uma fé inteligente, porque se Deus é conosco." (Bispo Panceiro, Ponto de Luz, 16 de maio de 2009).
}

Junto com a alteração na abordagem dos depoimentos são transmitidas imagens gravadas dos cultos da Universal e a reportagem passa a retratar as mudanças positivas proporcionadas pela fé em Deus. A partir do momento em que os entrevistados começam a relatar as mudanças em suas vidas, o GC passa a exibir informações diversificadas, como a sintonia da Rede Aleluia, o telefone do S.O.S. Espiritual, o site da Arca Media ou os horários dos cultos e endereços das igrejas.

No intervalo dos depoimentos, o apresentador comenta os 'piores' pontos da matéria anterior e vincula o assunto com o que está para ser exibido, além de também comentar sobre as pessoas que o procuram buscando ajuda e auxílio espiritual. Nesse dia em específico, foram exibidos seis depoimentos: três em formato de entrevista e três elaborados como depoimento-reportagem. O bispo encerrou o programa chamando para as 
reuniões que iriam acontecer e os locais de realização. Ao final, geralmente, são exibidas vinhetas que convidam o telespectador para acessar alguma mídia da IURD, como o blog do bispo Edir Macedo, ou sites como www.eucreioemmilagres.com.br.

\section{Programa Ponto de Luz - TU Pampa- RS/ Rede TU!}

$\mathrm{Na}$ região central do estado do Rio Grande do Sul, o programa é exibido diariamente e tem duração de quarenta minutos. Inicia às sete e vinte da manhã e é transmitido pelo canal nove da TV a cabo ou pelo canal 4 da TV aberta. O Ponto de Luz é apresentado, na maioria das vezes, pelo pastor regional Léo Roberto, mas há também apresentações do pastor Douglas Amaro.

Os programas exibidos regionalmente no centro do estado do Rio Grande do Sul são gravados na capital, Porto Alegre. Uma produtora, contratada pela IURD, edita os depoimentos, insere trilhas sonoras e finaliza os testemunhos, que dão subsídios para a apresentação. O pastor tem a função de comunicar-se com os telespectadores, todavia, está munido de um material (testemunhos, imagens de templos lotados, trilhas, vinhetas, etc,) produzido em outros locais, especialmente, no centro do país. Esse material, sobretudo com testemunhos, é gravado em estúdios e templos. Todas as semanas, os pastores regionais se reúnem na cidade de Porto Alegre, onde gravam depoimentos que serão inseridos durante os programas.

Nos primeiros momentos do programa, o pastor trata de estabelecer um diálogo com o telespectador. Os que assistem o Ponto de Luz são incitados a se sentir parte, como remete o enunciado: "Se você está sofrendo, este é o endereço da sua felicidade: Rua Angelo Uglione 1567, Santa Maria. Através do programa Ponto de Luz, você vai ver que existe uma solução para todos os seus problemas".

No programa da sexta-feira, dia 24 de abril, por exemplo, o pastor diz: "Você que está desesperado, que está aflito, que se encontra carregado...”. Depois de enunciar vários tipos de sofrimentos ele convida para o Desafio da Cruz, chamando um testemunho, num bloco que entra sob o título: "Eu era um caso perdido".

Neste momento, uma entrevistadora-jornalista pergunta a pessoas que circulam pelas ruas: "você acha que alguém que está com problema financeiros, amorosos, familiares é considerado um caso perdido?”. Depois de dadas as respostas, a testemunha começa o depoimento dizendo: "Eu era um caso perdido". Sentada em uma poltrona, a mulher conta sua história. O cenário dispõe de uma cortina vermelha e um aparelho de 
televisão. Na tela do aparelho, escrito em branco, sob um fundo vermelho, aparece a frase: "Eu era um caso perdido". Enquanto a mulher fala, uma pomba branca conduz os créditos com o nome dela no monitor. A roupa da testemunha possui a cor vermelha, a poltrona em que está sentada também é vermelha. Logo, aparece na tela da TV uma legenda onde está escrito: "venha passar pela cruz iluminada", junto estão os respectivos dias, horários e endereço da igreja na cidade de Santa Maria, interior do Rio Grande do Sul.

Depois do testemunho, o pastor Léo Roberto volta a aparecer no estúdio e usa o caso da testemunha para dizer aos ouvintes que a vida deles também pode mudar. Na tela, aparece outra legenda, agora, está escrito: "Receba uma orientação do pastor Léo: e-mail: pr.leosantos@hotmail.com”.

No momento seguinte, o pastor pede para que entre a imagem da cruz iluminada. Assim que a cruz aparece, ele diz: "É por essa cruz que você vai passar hoje. De repente, só de você olhar para esta cruz já esta lhe dando um arrepio, um calafrio (...). Só de olhar para a cruz você esta sentindo uma mal estar". Logo ele enuncia: "Ao passar pela cruz, o mal irá sair por total e completo".

No bloco seguinte, o pastor fala para os telespectadores sobre os dez sintomas de influência de encostos. Neste instante, dá-se início a uma série de imagens ilustrativas aos ditos dez sintomas, que são: nervosismo, dores de cabeça constantes, insônia, medo, desmaios constantes, desejo de suicídio, visão de vultos ou audição de vozes, doenças que os médicos não descobrem as causas, vícios, depressão. Logo depois do vídeo, o apresentador afirma que certamente alguns telespectadores se identificaram com um ou mais sintomas. Novamente, ele convida o público para conhecer a igreja.

No momento seguinte entra outro testemunho da série "Eu era um caso perdido". Depois disso, ele volta e chama o intervalo, no qual aparecem cenas de igrejas lotadas com uma narração que fala sobre o domingo, o dia da transformação familiar. Nos minutos finais, ele reafirma o nome da Igreja Universal do Reino de Deus. Além disso, é dito que no domingo eles estarão consagrando todos os auxiliares do bispo Macedo.

O programa termina com o pastor Léo no estúdio, lançando questionamentos como: Vamos falar com Deus? Vamos invocar a Deus? Já preparou seu copo com água? Depois ele começa a orar, fala da corrente de fé, e neste momento entra uma trilha sonora leve acompanhada de imagens de paisagens. 


\section{Considerações finais}

Por meio da análise dos programas, pôde-se constatar que os programas Ponto de Luz transmitidos pela Rede Record/Rede TV!, de São Paulo, e pela TV Pampa/Rede TV!, de Santa Maria, embora produzidos pela mesma denominação religiosa, possuem características que os identificam, simultaneamente, como similares e distintos. Entre os elementos compartilhados se fazem presentes aqueles de ordem técnica, a duração e a presença de vinhetas, como o tipo de discurso, pois envolve a mesma temática, tais como os problemas financeiros, familiares, afetivos, entre outros.

Assim como acontece com o cenário, a enunciação se configura como outra forma de diferenciação mais marcante entre os programas. Enquanto na versão local é detectado um detalhamento dos problemas vivenciados pelos fiéis, no programa gravado em São Paulo predomina uma maior presença de depoimentos e interação com os fiéis. O que, por sua vez, propicia que a descrição feita pelo apresentador, e através dos elementos e problemas enunciados, 'toque' e se aproxime do cotidiano experimentado pelos telespectadores que o estão assistindo.

Entretanto, embora as duas "versões" do programa pertençam à mesma denominação, o Ponto de Luz da Pampa/Rede TV! conta com uma produção e apresentação de pastor local, tendo como estratégia principal chamar as pessoas para o templo mais próximo de suas casas. Esse formato, no entanto, parece não ser capaz de estreitar laços com os telespectadores, já que se restringe a informar a localização do templo em Santa Maria, os horários e os cultos realizados. Compreende-se que para haver uma melhor aproximação seriam necessárias outras estratégias enunciativas, como trazer testemunhos locais, mostrar imagens dos templos localizados na região abrangida pelo programa e comentar as questões apresentadas nos relatos.

Dessa forma, a IURD, através do programa Ponto de Luz e dos elementos técnicos e dispositivos que o compõe, consegue se retroalimentar. Ou seja, ela reforça o vínculo com seus fiéis midiatizando seus preceitos religiosos e, em paralelo, também apresenta a potenciais seguidores alguns resultados da fé iurdiana. 


\section{Referências Bibliográficas}

BEHS, Micael Vier. Estratégias jornalísticas da Igreja Universal do Reino de Deus nas eleições 2006/2008: O caso da Folha Universal. São Leopoldo, 2009, 171p. Dissertação (Mestrado em Ciências da Comunicação). Centro de Ciências da Comunicação, Universidade do Vale do Rio dos Sinos.

E Deus fez o homem... e a igreja tornou-se mídia. Trabalho apresentado no Encontro da Rede Prosul - Comunicação, Sociedade e Sentido. UNISINOS. PPGCC, São Leopoldo, 2007.

CHARAUDEAU, Patrick. Discurso das Mídias. São Paulo: Contexto, 2007.

FAUSTO NETO, Antônio. Midiatização, prática social - prática de sentido. Trabalho apresentado no Encontro da Rede Prosul - Comunicação, Sociedade e Sentido, no seminário sobre Midiatização, UNISINOS. PPGCC, São Leopoldo, RS, Brasil.

FONSECA, Alexandre Brasil. Fé na tela: características e ênfases de duas estratégias evangélicas na televisão. In: Religião e Sociedade, Rio de Janeiro: ISER, v. 23, n. 2, p. 33-52, 2003a.

. Igreja Universal: Um império midiático. In: CORTEN, A., ORO, A.P., DOZON, J. Igreja Universal do Reino de Deus: os novos conquistadores da fé. São Paulo: Paulinas, 2003b. p. 259-280.

GOMES, Pedro Gilberto. A chamada 'Igreja Eletrônica' - conceitos envolvidos. In: Sierra Gutiérrez, Luis Ignacio (org.) Religião da mídia: Credibilidades em tensão. Unisinos, São Leopoldo, RS, Brasil, 2006. CD Edição Limitada. P. 9-27.

RODRIGUES, Adriano Duarte. Experiência, modernidade e campo dos media. Universidade Nova de Lisboa, 1999. 
Comunicação e Cultura, a experiência cultural na era da informação. Editora Presença; 1994.

VERÓN, Eliseo. Esquema para el análisis de la mediatización. In Revista Diálogos de la Comunicación, n.48, Lima: Felafacs, 1997. 